\title{
Accomplishments of Tea Research in Uganda in the Year 2019
}

\author{
Ronald Kawooya
}

\section{ABSTRACT}

\begin{abstract}
Tea is Uganda's third most important export earner and oscillates between coffee and fish. The current production in the country is 59,000 tonnes of made tea per year, earning 104 million United States Dollars to the Uganda's economy. Despite its importance to Uganda, the tea sector is faced with a number of constraints that include rising production costs, age of tea bushes, high overhead costs, poor agronomic agricultural practices, pests and diseases, low genetic potential, poor seed system, low labour productivity, and climate change. Since the collapse of Tea Research Institute of East Africa, tea research in Uganda has been dormant for three decades, due to limitations in tea experts, finance, and infrastructure. This review paper highlights the current tea research accomplishments made with the help of government of Uganda Agricultural Technology and Agribusiness Advisory Service (ATAAS) funding. These endeavors include: a) Genetic structure of tea diversity in Uganda has been determined, b) Characterization of tea clones with desirable attributes initiated, c) Soil nutrient up take of tea clones has been determined, d) Screening tea clones for resistance to Xylaria and Armillaria diseases and e) Tea dissemination material accomplished. This paper further spells out the future perspective and strategic intervention of tea research in Uganda.
\end{abstract}

Keywords: Tea, Research, ATAAS, Endeavors, Strategic, Intervention, Uganda.

\section{INTRODUCTION}

Tea is the cheapest hot beverage in the world and three billion cups of tea are drunk daily worldwide [1]. In Africa, Uganda is the third leading producer and exporter of tea $(45,000 \mathrm{MT})$ after Kenya $(295,000 \mathrm{MT})$ and Malawi (55,000MT) [2]. Tea is Uganda's third most important export earner and oscillates between coffee and fish [3]. Uganda earns 90 to 104 million USD from tea [4]. Approximately, $1,000,000$ people directly derive their livelihood from tea growing in Uganda [5].

In most tea producing countries, tea research is at the centre of tea development. In 1951, the Tea Research Institute of East Africa (TRIEA) was formed to provide tea research to Kenya. But from 1957 to 1959, TRIEA's mandate was extended to include Uganda and Tanzania. TRIEA's mandate was to conduct research and propagate clonal tea in the East Africa region. TRIEA was financed by access charged on tea production in Kenya, Uganda and Tanzania.

The collapse of the Eastern African Community (EAC) in 1975 is widely associated with the collapse of TRIEA. Since the collapse of TRIEA, tea research in Uganda has been dormant for three decades, due to limitations in tea experts, finance and infrastructure. Rwebitaba Tea Research Centre (TRC) recently in 2015 was given a mandate by the National Agriculture Research Organisation (NARO) to spear head and revive tea research in Uganda.
Published Online: January 23, 2021

ISSN: $2684-1827$

DOI: 10.24018 /ejfood.2021.3.1.214

\section{Ronald Kawooya *}

Rwebitaba Tea Research Station, Rwebitaba Zonal Agricultural Research and Development Institute, Uganda. (e-mail: kawoox2012@gmail.com)

*Corresponding Author

\section{OBJECTIVE}

The objective of this paper is to describe the progress of key impactful tea research achievements with the help of Agricultural Technology and Agribusiness Advisory Service (ATAAS) funding in three years 2016 to 2019 and also gives the future strategic direction of tea research in Uganda.

\section{Methodology}

Tea research in Uganda recently in 2012 has been revived and exclusively carried out by Rwebitaba Tea Research Station which is among the Public Agricultural Research Institutes [PARIs] of the National Agricultural Research Organization. Accordingly, the tea research institute and other PARIs were the primary source of published and or unpublished data or information. Additional information gathered for this review paper was collected using secondary data from different sources including tertiary institutions libraries. Also, an exclusive literature search was carried out at Rwebitaba Tea Research Station. Other secondary data sources [with data sets from Uganda] were collected from several other relevant journals, textbooks, and conference proceedings. Appointments with retired and or serving tea research scientists and technicians that were involved in tea research were also sought to give their personal insights. 


\section{RESUlTS AND DisCUSSION}

\section{A. Genetic Structure of Tea Diversity in Uganda Has Been Determined}

There are several uncharacterized clonal, seedling and seed barie accessions at the Rwebitaba Tea Research Center (RTRC). The clonal and seedling teas have been used as source of planting material across the country. For instance, out of the 278 clones, only five $(6 / 8,31 / 8,108 / 82,100 / 5$ and $303 / 577$ ) are formally being utilized on commercial scale to generate planting materials for farmers. However, the identity and genetic relationships of the existing clonal, seedling and exotic introductions and parental genotypes is not known thus limiting their effective use in breeding and commercial production in the country. The present study reports on progress made towards understanding genetic relationships among the clonal tea germplasm presently available at RTRC. A total 110 tea accessions of which 90 were from clonal field trials, and 20 from seed barie (SB) were sampled and genotyped with 10 microsatellite markers (Fig. 1). One of the accessions failed to amplify across all 10 microsatellites and therefore was excluded from further analysis. Accessions were broadly grouped into two main clusters, cluster C I (68 accessions) and cluster C II (39 accessions), and an out-group made of two accessions. Similarity among accessions was highest in cluster $\mathrm{C}$ I with 15 accessions within six sub-subclusters having similarity indices of 1.00 . Highest diversity was found in cluster C II with no two accessions having a similarity index beyond 0.95 . Two broad groups of tea genotypes exist at RTRC with the highest diversity found in cluster C II. Fingerprinting of more accessions from both onstation (RTRC) and on-farm across all major tea growing areas of Uganda would give a better understanding of the level of diversity available in the country.

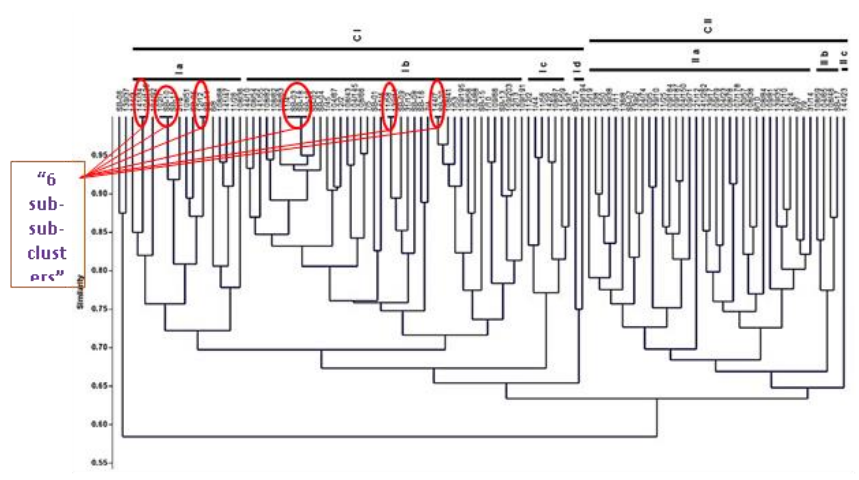

Fig. 1. Dendogram showing the genetic diversity of tea clones at Rwebitaba Tea Research Station as described in the write up.

\section{B. Developed and Characterized Tea Clones with Desirable Attributes}

In Uganda, small holder farmers entirely rely on the tea clones that were released in 1962 thus the existing tea plantations are above 50 years old. From the survey [7] carried out, most of the small-scale farmers just inherited the tea gardens from their parents and others bought land which had the tea field, therefore indicating a wide gap of the available clones. These results further stress that Ugandan farmers lack high quality planting materials which are tolerant to diseases since the current ones are now regarded as landraces. Characterization of germplasm is an important initial step towards proper utilization of genetic resources in plant breeding programs. Tea germplasm accessions conserved infield gene banks in Rwebitaba ZARDI of Uganda have not been adequately characterized and utilized in tea breeding programs.

Therefore, developing elite and high value tea varieties that combine multiple desirable traits using molecular techniques as well as enhancing the utilization of high-quality clones that offer environmentally-sound, long-term and sustainable crop protection for subsistence resource-limited farmers at little cost. The systematic evaluation of tea germplasms will provide elite materials both for individual selection and parental selection for hybridization. Eleven biochemical descriptors (Color, crude fibre, dry mater, fermentation, flavonoids, polyphenol, tannins, amino acid, brightness, caffeine, catechin) were used to score 51 accessions. The following Tea clones selected based on Tea Quality Index $100 / 15,108 / 78,11 / 56,141 / 262,144 / 17,144 / 3,31 / 11,6 / 8$ and will be further used for tea breeding purposes.

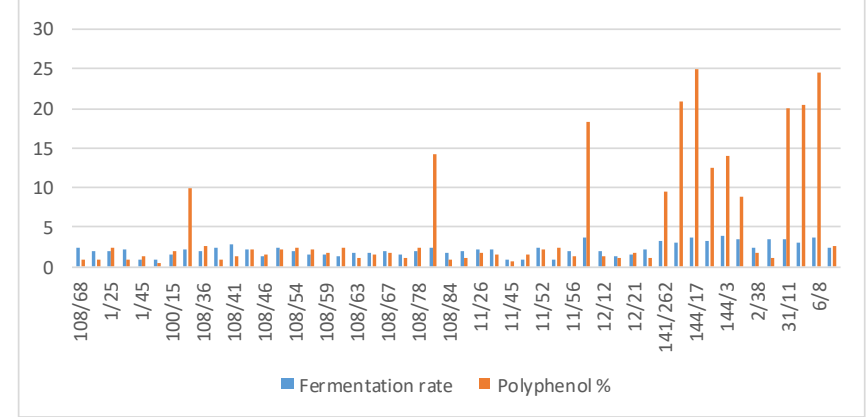

Fig. 2. Biochemical Analysis graph showing clones suitable for black tea based on percentage polyphenol.

\section{Soil Nutrient Up Take of Tea Clones Has Been Determined}

The soil under tea, over a long period of time, undergoes deterioration in relation to its structure and nutrient status. An integrated nutrient management system involving the use of organic manures, biofertilizers and synthetic fertilizers is one of the urgent tea research attention needs in Uganda. In addition, fertilizer application rates and regimes for optimal yield of tea is also under investigation at Rwebitaba Tea Research Center.

Results indicate that tea clones $6 / 8,6 / 10,108 / 82,100 / 5$, $144 / 23,112 / 2,108 / 43,31 / 11,141 / 34$ \& 144/3 were better at acquisition of nutrients (Figure 1). In addition, $60 \mathrm{~g}$ per tea bush (NPK 25:5:5) was the best rate as it gave the most yield an average of $0.3 \mathrm{Kg}$ per bush (Although the rates 120 and 200 $\mathrm{g}$ per bush also gave high yields, they were uneconomical) (Fig. 3). 


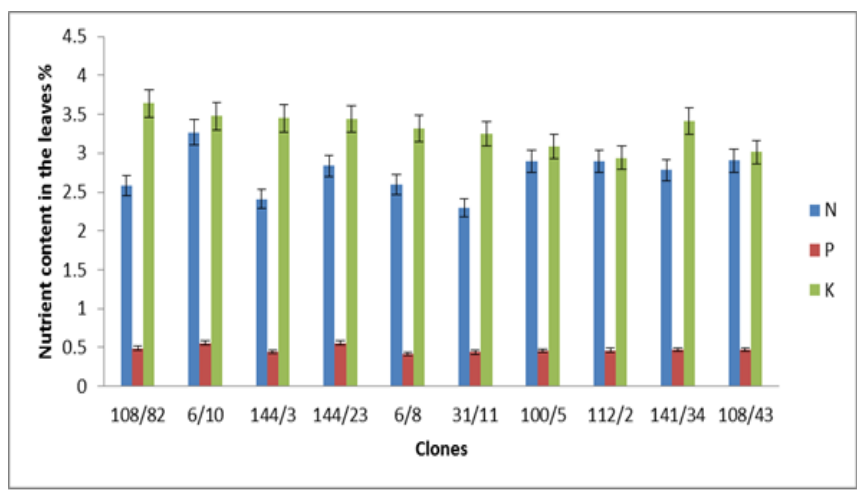

Fig. 3. Percentage of nutrient content in the leaves of different tea clones.

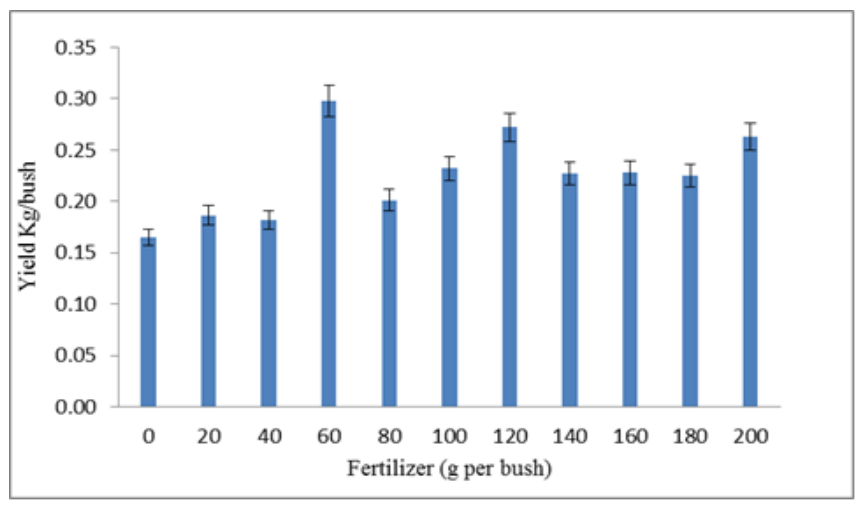

Fig. 4. Average yield per tea clone bush.

\section{Screening Tea Clones for Resistance to Xylaria and Armillaria Diseases}

In Uganda the key diseases of tea include Xylaria root, Armylaria root, dumping off, stem and root canker. These diseases cause a lot of yield losses for example in Kenya armylaria root is known causes 50\% loss in small holder farmers [6]. In Uganda Preliminary tea disease mappings puts the prevalence of Xyllaria disease at $36 \%$ while that of Armylaria disease at $15.9 \%$. Despite of this devastating nature of these two pathogens there has been no deliberate attempt to research on Armyllaria mellea and Xyalaria ssp since the inception of tea growing in 1908 [1]. This is the first time an attempt is being made to systematically gather information on differential resistance of Ugandan tea clones to Xylaria and Armylaria root. This information would give us an in-depth knowledge on Armylaria and Xylaria Pathogens, pathogen epedimiology, favourable environmental condition that promote disease spread and durable control of those diseases.

The pathogens were isolated from the collected specimen and identified preliminarily by cultural and microscopic methods. Confirmatory test was done by molecular method where DNA was extracted from every isolate, identified by molecular method and characterized for diversity test. Four clones (303/577,31/8, 6/8 and 108/82) were inoculate using four method and these included (Dead roots of tea bushes, Infected soils, Stem Plug (isolated inoculum) and Control (only sterilized soils). Dead roots of tea bushes were effective in infecting the tea seedlings. Pure cultures of Xyllaria isolated, preserved and will be used for inoculating more clones of tea to test for susceptibility.

\section{E. Tea Dissemination Materials}

Several awareness materials covering the recommended agronomic management of tea, tea nursery management, field establishment, bring tea into bearing, post-harvest handling of tea have all been produced and availed to tea farmers. 5 Brochures (Nursery management, tea establishment, Bringing tea into bearing, Pests and diseases of tea, tea Value Addition). 2 Posters (pests and diseases of tea) and 2 Television Documentaries (Uganda Broadcasting Television Documentary on tea nursery management, Tea Field management) have been done.
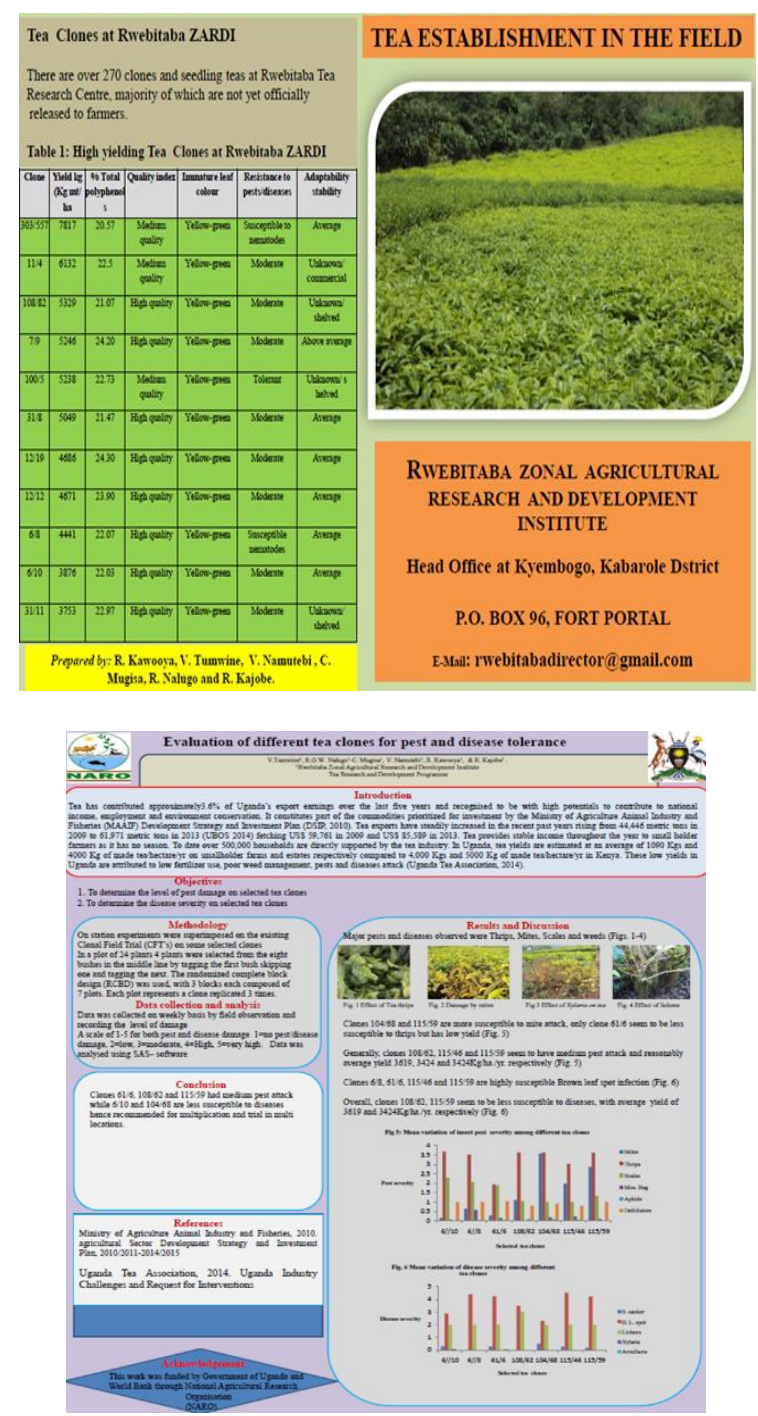

Fig. 5. Tea dissemination materials.

\section{F. Key Areas of Future and Strategic Tea Research in Uganda}

The future strategic intervention in tea research will involve; Crop Improvement were research and development activities will be focused on incorporating desirable attributes into existing cultivars, to increase growers' acceptability and meet the diverse needs of end users. Land productivity improvement were research and development will address the increasing productivity through soil fertility improvement and agronomic practices. Impacts of Climatic Change, Adaptation and Mitigation Strategies were assessment of the impact of global climate change on productivity and profitability of the tea industry in Uganda will be done. 
Mechanization of field practices were development of appropriate mechanical devices and agronomic practices to overcome labour shortage in tea growing areas in Uganda. Crop Management were integrated crop protection approaches to minimize economic damage and address health, safety and environmental issues. Development of cost-effective control methods for integrated management of major tea pests, tea diseases and weed management strategies in tea. Value Added Tea Products were value addition, new product development and product diversification of tea for commercialization.

\section{CONCLUSION}

The main conclusion is the need to invest in all aspects of tea research [Crop improvement, Land productivity improvement, Impacts of climate change adaptation and mitigation strategies, Mechanization of field practices and Value addition of tea products]. In addition, there is a need to integrate research for development programmes that are able to address the multiple production constraints of tea and thereby significantly contribute to improving the livelihoods of smallholder tea farmers.

\section{ACKNOWLEDGMENT}

This paper has been possible because of the funding from government of Uganda through the Agricultural Technology and Agribusiness Advisory Service (ATAAS) project managed by the National Agricultural Research Organization.

\section{REFERENCES}

[1] O'Connor [1965]. The geography of tea and sugar production in Uganda. E. Africa. Geogr. Rev., No.3, April 1965, pp. 27-35.

[2] MAAIF [2012]. Operationalization of the non- ATAAS component of the development strategy and investment plan: Draft analytical report on the tea value chain.

[3] National Planning Authority[(NPA] [2007]. Feasibility Study for expanding Tea Production and establishing a Tea Factory in Kabale District.

[4] Munyambonera. F, Lakuma. C, and Guloba. M., [2014]. Uganda's Tea Sub Sector: A comparative Review of Trends, Challenges and Coordination failures. Pg 2-8.

[5] MAAIF (2016). Ministry of Agriculture Animal Industry and Fisheries Policy Statement.

[6] Onduru, D.D., Muchena, F.M., Gachimbi, L. and Maina, F. [2002]. Experiences with Farmer Field Schools in Kenya: Literature review on IPM, IPPM and INM. INMASP Report No. 1. ETC East Africa and Kenya Agricultural Research Institute, Nairobi, Kenya.

[7] Rwebitaba, 2015 unpublished. Survey on tea production constraints by smallholder farmers in Uganda.

Kawooya Ronald was born in Uganda on 23rd March 1985. He graduated with a Master's Degree in Crop Science from Makerere University Kampala Uganda. He is a multi-skilled professional with ten years of relevant and progressive research experience in Crop Science, Agronomy, Soil science, Agricultural botany and plant physiology, Weed Science, Farming Systems, Pest and Disease Management and Breeding. Presently he is working as a research officer under Crop and Natural Resources Research Programme with National Agricultural Research Organisation (NARO) based at Rwebitaba Zonal Agricultural Research and Development Institute, Kyembogo, Fort Portal, Uganda. 